\title{
Tolerância a metais pesados e produção de surfactante por Pseudomonas fluorescens Slim15
}

\author{
Heavy metal tolerance and production of surfactant by Pseudomonas fluorescens Slim15
}

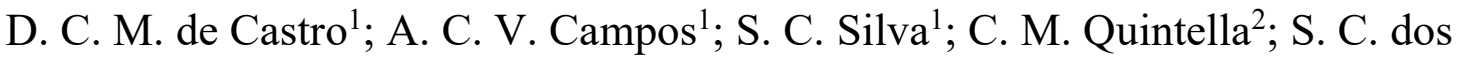 \\ Santos ${ }^{1 *}$ \\ ${ }^{1}$ Universidade Federal do Sul e Sudeste do Pará (Unifesspa), 68507-590, Marabá-PA, Brasil \\ ${ }^{2}$ Universidade Federal da Bahia (UFBA), 40170-290, Salvador-BA, Brasil.
}

*sidnei.cerqueiradossantos@gmail.com

(Recebido em 03 de fevereiro de 2020; aceito em 15 de outubro de 2020)

\begin{abstract}
$\mathrm{O}$ descarte inadequado de resíduos industriais ou acidentes ambientais tem causado grandes impactos ambientais, como a contaminação por metais pesados. Processos biotecnológicos envolvendo microrganismos têm sido utilizados como estratégia para recuperar ambientes impactados. $\mathrm{O}$ objetivo deste trabalho foi avaliar a influência de metais pesados essencial e não essencial no crescimento e na produção de surfactante da linhagem Pseudomonas fluorescens Slim15. Os testes de concentração inibitória mínima (CIM) e concentração bactericida mínima (CBM) foram utilizados para avaliar a tolerância aos metais $\mathrm{Pb}$ e Zn. Foram realizados testes de atividade emulsificante e tensão superficial para avaliar a influência dos metais na produção de biossurfactante. A linhagem $P$. fluorescens Slim15 apresentou crescimento na presença de $31,25 \mathrm{mg} / \mathrm{L}$ de $\mathrm{Zn}$ e de $1000 \mathrm{mg} / \mathrm{L}$ de $\mathrm{Pb}$ no teste CIM e de $4000 \mathrm{mg} / \mathrm{L}$ no teste CBM para os metais testados. Os metais não apresentaram influência significativa na produção de biossurfactante. Esta pesquisa mostrou que a linhagem $P$. fluorescens $\operatorname{Slim} 15$ apresentou rendimento satisfatório nos testes de tolerância e produção de surfactante, mesmo em altas concentrações de metais. Esta linhagem bacteriana é uma promissora agente biorremediadora de ambientes contaminados por metais pesados.
\end{abstract}

Palavras-chave: resíduo industrial, biorremediação, biossurfactante

Inadequate disposal of industrial waste or environmental accidents has caused major environmental impacts, such as the heavy metal contamination. Biotechnological processes involving microorganisms have been used as a strategy to recover impacted environments. The aim of this study was to evaluate the influence of essential and non-essential heavy metals on the growth and the surfactant production from Pseudomonas fluorescens Slim15 strain. Minimum inhibitory concentration (MIC) and the minimum bactericidal concentration (MBC) tests were used to evaluate the tolerance to metals $\mathrm{Pb}$ and $\mathrm{Zn}$. Emulsifying activity and surface tension tests were carried out to evaluate the influence of the metals on the biosurfactant production. P. fluorescens Slim 15 strain presented growth in presence up to $31.25 \mathrm{mg} / \mathrm{L}$ of $\mathrm{Zn}$ and $1000 \mathrm{mg} / \mathrm{L}$ of $\mathrm{Pb}$ in the MIC test, and of $4000 \mathrm{mg} / \mathrm{L}$ in the MBC test for tested metals. The metals did not have a significant influence on the biosurfactant production. This research showed that $P$. fluorescens Slim15 strain had satisfactory yield in the tolerance and surfactant production tests, even in high concentrations of metals. This bacterium strain is a promising bioremediation agent of environments contaminated by heavy metals.

Keywords: industrial waste, bioremediation, biosurfactant

\section{INTRODUÇÃO}

Metais pesados é normalmente definido como um grupo heterogêneo de elementos com a densidade acima de $5 \mathrm{~g} / \mathrm{cm} 3$, incluindo metais e semimetais [1]. Estes são divididos em essencial e não essencial. Os metais essenciais ou micronutrientes são utilizados nos processos físiológicos das células e tecidos, incluindo cobalto, cobre, zinco, porém, em altas concentrações podem formar complexos inespecíficos potencialmente tóxicos aos organismos. Por outro lado, os metais não essenciais, como mercúrio, chumbo, cádmio, não possuem nenhuma função dentro dos organismos e a sua acumulação pode provocar graves doenças $[2,3]$.

A contaminação por metais pesados é um dos mais importantes problemas de poluição ambiental, devido à alta reatividade, capacidade de bioacumulação e biomagnificação, sendo capazes de alterar a diversidade, estrutura e função ecológica do ambiente contaminado [4, 5]. As 
principais causas de contaminação são a eliminação inadequada de resíduos industriais [6], a drenagem ácida de minas [7] e os acidentes ambientais associados à atividade mineradora, como o rompimento nas barragens de rejeito de Mariana em 2015 (Samarco Mineração S.A.) e de Brumadinho em 2019 (Mineradora Vale S.A), ambos ocorridos em Minais Gerais, Brasil. Os efeitos do metal pesado podem ser imediatos, como também podem ser nocivos em médio ou longo prazo, visto que a contaminação é progressiva e cumulativa.

A atividade biológica natural promove a despoluição do ambiente por meio de processos metabólicos dos microrganismos, conhecido como biorremediação intrínseca [8]. Esse processo é limitado principalmente a quantidade, distribuição e natureza do contaminante, além da composição e abundância das comunidades microbianas [9]. No entanto, quando as condições ambientais não são favoráveis, é necessário o uso de processos de biorremediação a partir da intervenção humana. Nestes são utilizados agentes biológicos, normalmente microrganismos ou suas enzimas ou seus produtos metabólicos, para remover ou reduzir os contaminantes ambientais. A biorremediação de íons metálicos pode ocorrer por meio do processo de adsorção na superfície celular ou absorção no interior da célula microbiana, ou ainda de transformação, através de processos redox ou por alquilação $[10,11]$.

Os surfactantes microbianos apresentam propriedades de grande interesse biotecnológico, devido à baixa toxidade, biodegradabilidade, atividade emulsificante e tensoativa, e a possibilidade de produção a partir de fontes renováveis [12, 13, 14]. O uso de biossurfactantes para biorremediação de compostos inorgânicos baseia-se na capacidade de formar complexos com metais. As ligações entre metal e as micelas dos biossurfactantes podem ocorrer por atração entre tensoativos aniônicos e formas metálicas não iónicas, ou por formação de quelatos na superfície das micelas $[15,16,17]$.

De acordo com relatos da literatura, o biossurfactante da classe glicolipídio, produzido por Pseudomonas sp., é um dos mais eficiente e amplamente estudado [18, 19]. O gênero Pseudomonas é amplamente referenciado quanto a capacidade de tolerar a altas concentrações de metais pesados, como $\mathrm{Pb}$ e $\mathrm{Zn}$ [20, 21], de degradar compostos xenobióticos e de mobilizar íons metálicos, devido à diversidade metabólica e capacidade adaptativa a diversos ambientes, tornando-o um potencial agente biorremediador [22]. Nesse contexto, o objetivo deste trabalho foi avaliar a influência de metais pesados essencial e não essencial no crescimento e na produção de surfactante pela linhagem Pseudomonas fluorescens Slim15.

\section{MATERIAL E MÉTODOS}

\subsection{Linhagem bacteriana}

A linhagem Pseudomonas fluorescens Slim15, isolada no Parque Municipal de Mucugê, no estado da Bahia, Brasil [19], foi utilizada nos ensaios de tolerância e produção de biossurfactante. A linhagem bacteriana foi conservada no meio agar triptona de soja (TSA) (Kasvi) e mantida a $4{ }^{\circ} \mathrm{C}$ no Laboratório Multiuso de Biologia da Universidade Federal do Sul e Sudeste do Pará (Unifesspa).

\subsection{Metal pesado}

A solução mãe dos metais pesados foi preparada em água Milli-Q na concentração de 8.000 $\mathrm{mg} / \mathrm{L}$, usando os seguintes sais: nitrato de chumbo $\left[\mathrm{Pb}\left(\mathrm{NO}_{3}\right)_{2}\right]$ e sulfato de zinco $\left(\mathrm{ZnSO}_{4}\right)$, grau de pureza P.A., adquiridos da empresa Neon Comercial S.A. A solução mãe de cada metal foi esterilizada individualmente a $121^{\circ} \mathrm{C}$ por 20 minutos. $\mathrm{O}$ zinco foi escolhido como elemento essencial e o chumbo como não essencial.

\subsection{Teste de tolerância a metais pesados}

O teste de tolerância da linhagem $P$. fluorescens Slim15 aos metais pesados foi realizado a partir da determinação da concentração inibitória mínima (CIM) e da concentração bactericida mínima 
(CBM). A CIM foi realizada em placa para cultivo de células de 96 poços, contendo $90 \mu \mathrm{L}$ de caldo Mueller-Hinton (CMH). Cem microlitros da solução mãe dos metais $\mathrm{Pb}$ e $\mathrm{Zn}$ foram transferidos para os respectivos poços e diluídos, utilizando a técnica de diluição seriada, nas concentrações de 1,9 a $4.000 \mathrm{mg} / \mathrm{L}$. O inóculo bacteriano de $10 \mu \mathrm{L}$ foi aplicado em cada poço, ajustado a partir da escala 0,5 de McFarland (1,5 x $10^{8}$ bactérias/poço). Os controles (CMH, CMH e linhagem bacteriana, $\mathrm{CMH}$ e metal) foram realizados para maior confiabilidade do estudo. A placa foi incubada a $37^{\circ} \mathrm{C}$ por $24 \mathrm{~h}$, após esse período adicionou-se a solução reveladora cloreto de $2,3,5$ trifenil tetrazólio (TTC) e a placa foi incubada na estufa por mais 2 horas. A leitura foi realizada através da mudança de cor da solução reveladora, sendo considerado crescimento bacteriano a presença da cor rosa avermelhada e ausência de crescimento quando a cor do meio permaneceu inalterada [23].

A CBM teve como base os resultados do ensaio de CIM, sendo retirado uma alçada da cultura com o auxílio da alça bacteriológica, a partir dos poços que apresentaram inibição até a maior concentração testada, e semeada pela técnica de esgotamento em estrias na superfície do meio TSA contido em placa de Petri. A placa foi incubada na estufa a $37^{\circ} \mathrm{C}$ por 24 a 48 horas para avaliação de crescimento das colônias bacterianas.

\subsection{Influência de metais pesados na produção de biossurfactante}

A influência do tipo e da concentração dos metais testados foi avaliada a partir de duas propriedades do biossurfactante, atividade emulsificante e tensão superficial. A produção de biossurfactante foi realizada em frasco Erlenmeyer de $100 \mathrm{~mL}$ contendo $30 \mathrm{~mL}$ de meio salino mineral (MSM), com a seguinte composição (g/L): $\mathrm{K}_{2} \mathrm{HPO}_{4}, 4,0 \mathrm{~g} ; \mathrm{Na}_{2} \mathrm{HPO}_{4}, 1,5 \mathrm{~g}$; $\mathrm{NaNO}_{3}, 1,0 \mathrm{~g}$; $\mathrm{MgSO}_{4} .7 \mathrm{H}_{2} \mathrm{O}, 0,2 \mathrm{~g} ; \mathrm{CaCl}_{2} \cdot 2 \mathrm{H}_{2} \mathrm{O}, 0,02 \mathrm{~g} ; \mathrm{FeCl}_{3} \cdot 6 \mathrm{H}_{2} \mathrm{O}, 0,02 \mathrm{~g}$; glicerol, 0,5\% [24]. $\mathrm{O} \mathrm{pH}$ foi ajustado para 7.0 usando $\mathrm{HCl}$ ou $\mathrm{NaOH}$. O MSM foi esterilizado a $121^{\circ} \mathrm{C}$ por 20 minutos. Após a autoclavagem, foi transferido individualmente 14,$6 ; 29,2 ; 58,5$; e $117 \mu \mathrm{L}$ das soluções mãe de $\mathrm{Pb}$ e Zn, correspondente as concentrações de 3,9; 7,8; 15,6 e 31,25 mg/L, respectivamente. O inóculo de $2,5 \mathrm{~mL}$ da suspensão bacteriana $\left(1,5 \times 10^{8}\right.$ bactérias $\left./ \mathrm{mL}\right)$, ajustada conforme o teste de tolerância, foi adicionado no Erlenmeyer. A cultura foi incubada no agitador orbital (Quimis) na rotação de $180 \mathrm{rpm}, \mathrm{a} 30^{\circ} \mathrm{C}$ por 48 horas. Após essa etapa, a cultura foi centrifugada a $4000 \mathrm{rpm}$ por 30 minutos para obtenção do caldo livre de células [19].

A produção de biossurfactante foi avaliada através do índice de emulsificação ( $\mathrm{IE}_{24}$ ) [25]. Dois mililitros de óleo mineral (Nujol) e 2,0 mL do caldo livre de células foram transferidos para tubos de ensaio (100 mm x $15 \mathrm{~mm}$ ) e agitados no vórtex (Biomixer) por 2 minutos. Após 24 horas, o $\mathrm{IE}_{24}$ foi calculado usando a seguinte fórmula: $\mathrm{IE}_{24}(\%)=\mathrm{x} / \mathrm{y} \times 100$, onde $\mathrm{x}$ e y representam a altura da camada emulsificada $(\mathrm{mm})$ e a altura total $(\mathrm{mm})$, respectivamente. Os controles foram realizados com MSM não inoculado e MSM com as concentrações dos metais definidas neste estudo.

A tensão superficial (TS) do caldo livre de células foi realizada no tensiômetro (DataPhysics, Oca15 plus), através do método da gota pendente à temperatura de $25^{\circ} \mathrm{C}$ [26]. A tensão superficial da superfície da gota foi medida usando um sistema de imagem de vídeo automática e o programa Oca 10/Oca 20. O instrumento foi calibrado com ar e água destilada para uma leitura de 71,62 \pm $1.0 \mathrm{mN} / \mathrm{m}$ [27].

\subsection{Análise estatística}

Todos os testes foram realizados em triplicata. O banco de dados foi construído no programa Microsoft Excel 2013 para análise descritiva das variáveis. No programa SPSS 18.0 foi utilizado o teste $\mathrm{T}$ de Student para comparar médias de dois grupos com amostras relacionadas e o teste de Tukey para comparar as concentrações entre os metais, considerando resultados estatisticamente significativos para valores de $\mathrm{p} \leq 0,05$. 


\section{RESULTADOS E DISCUSSÃO}

\subsection{Tolerância a metais pesados}

Os resultados obtidos na determinação da concentração inibitória mínima demostram que a linhagem P. fluorescens Slim15 foi tolerante aos metais analisados, apresentando crescimento satisfatório na faixa de 1,9 a $31,25 \mathrm{mg} / \mathrm{L}$ de zinco e 1,9 a $1000 \mathrm{mg} / \mathrm{L}$ de chumbo (Figura 1). A inibição do crescimento foi observada a partir da concentração de $62,5 \mathrm{mg} / \mathrm{L}$ de zinco e de 2000 $\mathrm{mg} / \mathrm{L}$ de chumbo (Figura 1).

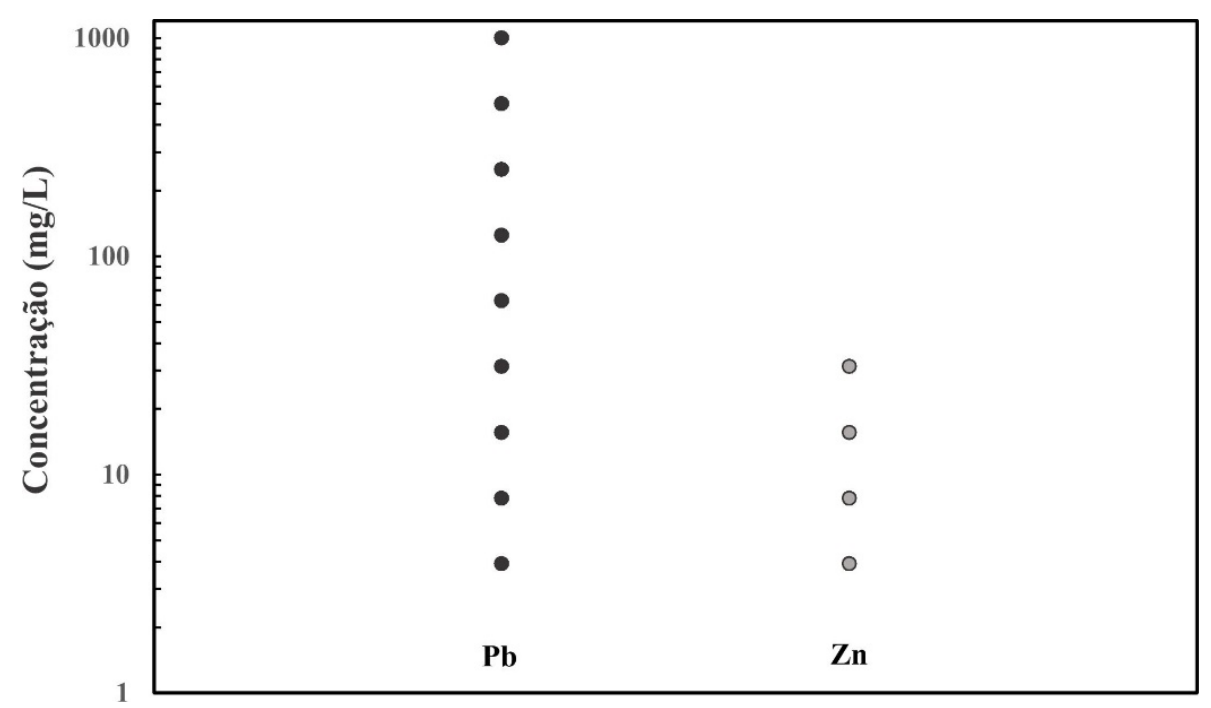

Figura 1: Tolerância da linhagem P. fluorescens Slim15 aos metais Pb e Zn em diferentes concentrações.

Segundo Alhasawi et al. (2015) [28], a espécie P. fluorescens possui capacidade de sobreviver em ambientes compostos por diversos metais, apresentando mudança metabólica que garante a sobrevivência e o sequestro de metais. Relatos da literatura tem mostrado que o gênero Pseudomonas é tolerante aos metais chumbo e zinco, apresentando uma faixa de crescimento bacteriano na concentração de 0,51 a $5 \mathrm{mg} / \mathrm{L}$ de $\mathrm{Pb}$ e de 0,39 a $6,2 \mathrm{mg} / \mathrm{L}$ de $\mathrm{Zn}$, por meio da determinação da CIM [21, 29, 30, 31]. A linhagem $P$. fluorescens Slim15 apresentou melhor perfil de tolerância aos metais testados quando comparado com os resultados dos trabalhos citados, entretanto, é importante ressaltar que as condições de cultivo podem influenciar os resultados.

A adaptação microbiana é um mecanismo fundamental de resposta à presença de contaminantes, ambientes hostis (como alta salinidade, concentração de metal), antibióticos, entre outras condições adversas [32]. A presença de íons metálicos pode induzir os genes das bactérias a desenvolver mecanismos de tolerância aos metais, como $\mathrm{Pb}, \mathrm{Cd}, \mathrm{Hg}, \mathrm{Ni}, \mathrm{Zn}$, entre outros, por meio da adsorção à parede celular, transporte através da membrana celular, armazenamento extracelular em cápsulas, precipitação ou por produção de metabólitos secundário bioemulsificantes [33, 34]. Estes mecanismos podem transcorrer por plasmídeos ou DNA cromossômico em diversas bactérias [33, 35].

A avaliação da concentração bactericida mínima foi realizada a partir da concentração de 62,5 $\mathrm{mg} / \mathrm{L}$ de zinco e de $2000 \mathrm{mg} / \mathrm{L}$ de chumbo. A CBM necessária para matar a linhagem $P$. fluorescens Slim 15 foi de $4000 \mathrm{mg} / \mathrm{L}$ para os metais testados, sendo considerado a morte do microrganismo a ausência de colônias na superfície do meio TSA. A CBM de zinco foi 64 vezes maior que a CIM, enquanto que para o chumbo foi apenas duas vezes maior que a concentração necessária para inibir o crescimento da bactéria em estudo.

$\mathrm{O}$ efeito bactericida dos metais sobre as cepas bacterianas aumenta gradativamente com o aumento da concentração de metal. Os mecanismos de adaptação podem tornar-se ineficazes à medida que a concentração dos metais aumenta, ocorrendo a saturação desses íons nos 
microrganismos. Os íons metálicos interferem nas vias metabólicas das bactérias, competindo com os metais essenciais pelos sítios de ligação iônica, afetando a fosforilação oxidativa e bloqueando enzimas no sistema de transporte de nutrientes, podendo, dessa forma, inviabilizar a atividade metabólica de forma irreversível e levar a morte das células bacterianas [36, 37].

\subsection{Influência de metais pesados na produção de biossurfactante}

A linhagem $P$. fluorescens Slim15 apresentou atividade emulsificante na presença dos metais chumbo e zinco (Figura 2). A maior produção de emulsificado ocorreu na concentração de 15,6 $\mathrm{mg} / \mathrm{L}$ de $\mathrm{Zn}$ e houve redução gradativa no $\mathrm{IE}_{24}$ à medida que aumentou a concentração de $\mathrm{Pb}$ (Figura 2). Os controles positivos apresentaram $\mathrm{IE}_{24}$ de aproximadamente $59 \%$ e os negativos não apresentaram formação de emulsificado.

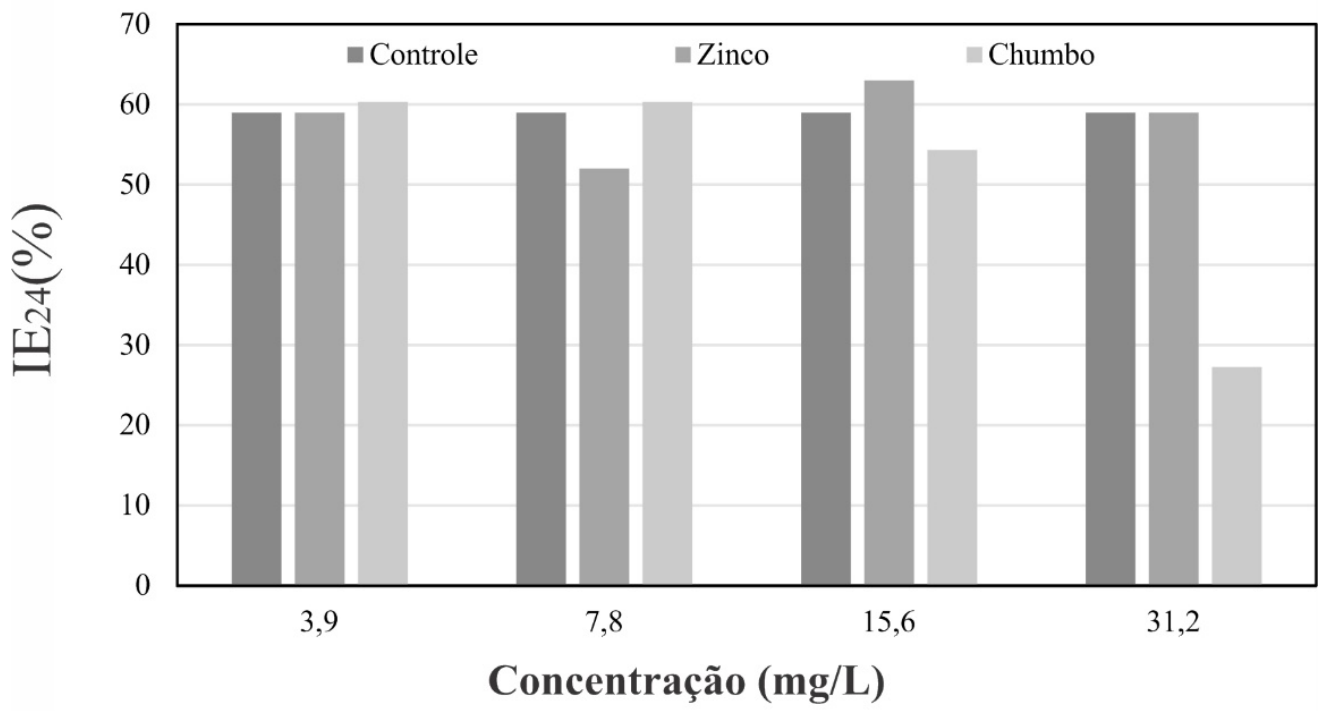

Figura 2: Índice de emulsificado do caldo livre de células de P. fluorescens Slim15 na presença de chumbo e zinco em diferentes concentrações.

De acordo com a análise estatística, houve diferença significativa $(p=0,039)$ de formação de emulsificado entre as concentrações de 15,6 e $31,25 \mathrm{mg} / \mathrm{L}$ de $\mathrm{Pb}$ quando comparadas com o controle, entretanto, não houve diferença entre as concentrações testadas (Figura 2). $\mathrm{O}$ ensaio com metal $\mathrm{Zn}$ apresentou a maior média de formação de emulsificado, contudo, os resultados não apresentaram diferença significativa $(p>0,05)$ em relação ao controle e nem entre as concentrações. Os resultados do teste de Tukey não indicaram diferenças estatisticamente significantes do $\mathrm{IE}_{24}$ nas comparações múltiplas entre os metais.

O índice de emulsificação é uma análise qualitativa que determina indiretamente a presença de biossurfactante no caldo livre de células, por meio da formação e da estabilidade do emulsificado [38]. Pinto, Martins e Costa (2009) [39] consideram que um bom agente emulsificante apresenta a habilidade de formar pelo menos $50 \%$ de emulsão e mantê-lo estável no período de 24 horas, utilizando óleo a base de hidrocarboneto na determinação do índice de emulsificação. Neste estudo, foi observado que a presença de $\mathrm{Zn}$ não influenciou na produção de emulsificado nas diferentes concentrações testadas e que o $\mathrm{Pb}$ reduziu apenas na concentração de $31,25 \mathrm{mg} / \mathrm{L}$. Rizzo et al. (2015) [40] também relataram que a produção de emulsificado (57\% e $63 \%)$ do caldo livre de células da linhagem Joostella A8 foi estável na presença de 10 e $100 \mathrm{mg} \cdot \mathrm{L}^{-1} \mathrm{de} \mathrm{Zn}$, respectivamente, sugerindo que o biossurfactante pode atuar como um agente adaptativo estratégico para defender as células de uma condição de estresse por metais pesados. Por outro lado, Rizzo e Giudice (2018) [41] observaram que na presença de $100 \mathrm{mg} / \mathrm{L}$ de $\mathrm{Zn}$ houve redução de $66 \%$ para menos de $45 \%$ da produção de emulsificado do caldo livre de células da linhagem Alcanivorax sp. A53. 
O surfactante produzido pela linhagem $P$. fluorescens Slim15 foi capaz de reduzir a tensão superficial de aproximadamente $71 \mathrm{mN} / \mathrm{m}$ (controle) para valores próximos de $30 \mathrm{mN} / \mathrm{m}$, na presença de diferentes concentrações de $\mathrm{Pb}$ e $\mathrm{Zn}$ (Figura 3). A análise estatística demonstrou que houve diferença significativa $(\mathrm{p}=0,001)$ da TS quando comparado com o controle, mas não houve entre os metais e suas respectivas concentrações. De acordo com Desai e Banat (1997) [42], um bom agente emulsificante deve reduzir a TS abaixo de $40 \mathrm{mN} / \mathrm{m}$. Estudos relatam que os surfactantes produzidos pelas espécies de Pseudomonas são capazes de reduzir a tensão superficial na faixa de 26 a $32 \mathrm{mN} / \mathrm{m}[12,13,19,43,44]$.

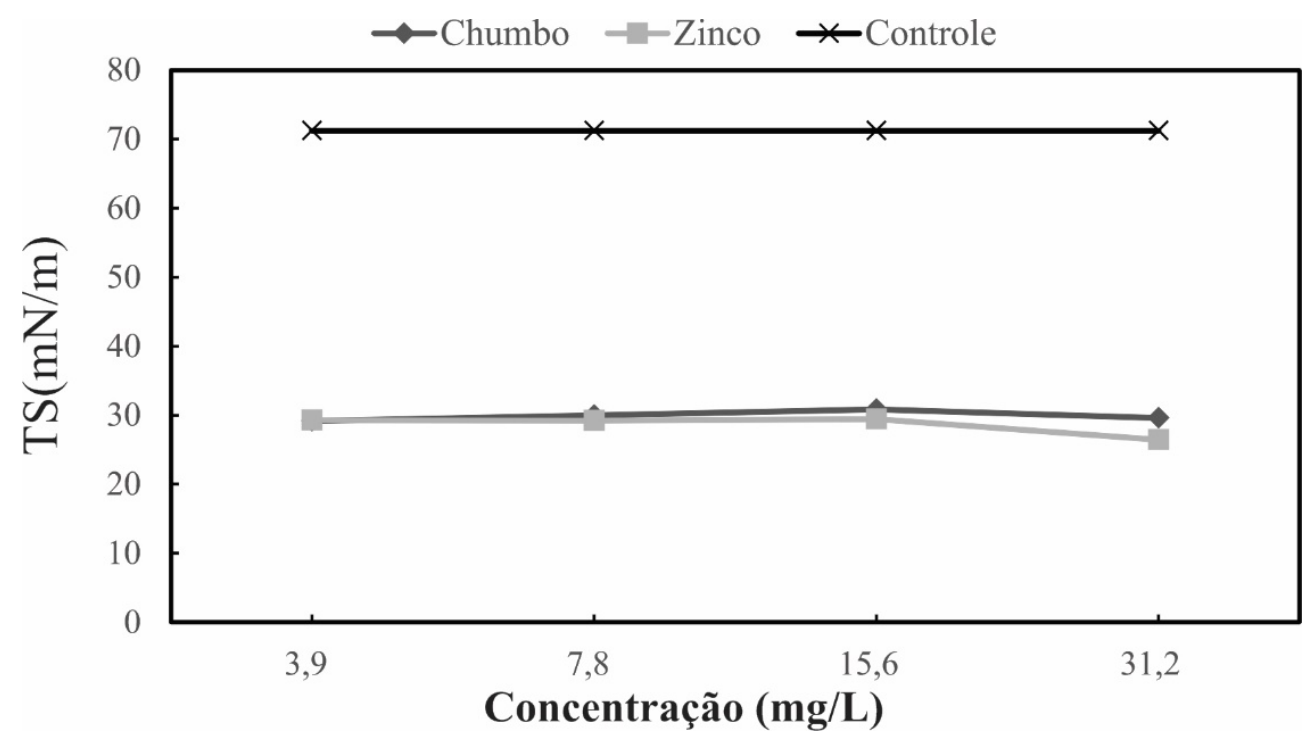

Figura 3: Tensão superficial do caldo livre de células de P. fluorescens Slim15 na presença de chumbo e zinco em diferentes concentrações.

Os resultados apresentados indicam que os metais $\mathrm{Pb}$ e $\mathrm{Zn}$ não influenciaram a redução da tensão superficial. Os autores não encontraram relatos na literatura relacionados com a influência de metais pesados sob a tensão superficial do caldo livre de células de espécies do gênero Pseudomonas. Entretanto, Rizzo e Giudice (2018) [41] relataram que o surfactante produzido pela linhagem Alcanivorax sp. A53 não reduziu a tensão superficial na presença de $100 \mathrm{mg} / \mathrm{L}$ de Zn, sendo que na ausência deste houve redução para $25 \mathrm{mN} / \mathrm{m}$ [44], indicando que este metal pode ter influenciado a capacidade da linhagem bacteriana de produzir biossurfactante [41].

A escolha do agente biorremediador é essencial para planejar o tratamento do ambiente contaminado, pois nem todas as cepas bacterianas são capazes de sobreviver e nem de manter a eficiência de produção de biossurfactante na presença de diferentes tipos e concentrações de metais peados. O estudo sobre a influência de metais na produção de biossurfactante é recente no mundo científico, havendo poucos relatos disponíveis na literatura. Este trabalho adiciona informação importante para o crescente conhecimento científico sobre os critérios de seleção de linhagens bacterianas produtoras de biossurfactante promissoras e sua potencialidade na biorremediação de ambientes impactados por metais.

\section{CONCLUSÃO}

Este trabalho indica que a linhagem $P$. fluorescens Slim15 foi tolerante aos metais chumbo e zinco e que estes não influenciaram na produção de biossurfactante nas concentrações testadas. A capacidade da linhagem bacteriana de crescer e produzir biossurfactante em altas concentrações de metais indica que esta é um agente biorremediador promissor tanto para aplicação em processo de bioaumentação quanto de bioestinulação, entretanto, é necessário a realização de mais estudos para entender o mecanismo de resistência da linhagem bacteriana (adsorção/acumulação/bombeamento) e a capacidade do surfactante de remover (complexar) metais pesados de amostras contaminadas. 
A aplicabilidade do surfactante biológico é cientificamente comprovada, possuindo peculiaridades que sobressai aos surfactantes industriais, tornando-se uma alternativa para o desenvolvimento de método de biorremediação de áreas contaminas por íons metálicos.

\section{AGRADECIMENTOS}

Agradecemos ao Laboratório de Cinética e Dinâmica Molecular (Lablaser) da Universidade Federal da Bahia (UFBA) pela colaboração na realização das análises de tensão superficial.

\section{REFERÊNCIAS BIBLIOGRÁFICAS}

1. Duffus JH. "Heavy metal": a meaningless term? Pure Appl Chem. 2002 Set;74(5):793-807, doi: 10.1515/ci.2001.23.6.163.

2. Guo J, Kang Y, Feng Y. Bioassessment of heavy metal toxicity and enhancement of heavy metal removal by sulfate-reducing bacteria in the presence of zero valent iron. J Environ Manage. 2017 Dec;203(1):278285, doi: 10.1016/j.jenvman.2017.07.075.

3. Rzymski P, Tomczyk K, Rzymski P, Poniedziałek B, Opala T, Wilczak M. Impact of heavy metals on the female reproductive system. Ann Agric Environ Med. 2015;22(2):259-264, doi: $10.5604 / 12321966.1152077$.

4. Chu D. Effects of heavy metals on soil microbial community. IOP Conf. Ser.: Earth Environ Sci. 2008;113(1):1-5, doi :10.1088/1755-1315/113/1/012009.

5. Hesse E, O'Brien S, Tromas N, Bayer F, Lujan AM, van Veen EM, Hodgson DJ, Buckling A. Ecological selection of siderophore-producing microbial taxa in response to heavy metal contamination. Ecol Lett. 2018 Jan;21(1):117-127, doi: 10.1111/ele.12878.

6. He ZL, Yang XE, Stoffella PJ. Trace elements in agroecosystems and impacts on the environment. J Trace Elem Med Biol. 2005 Oct;19(2-3):125-140, doi: 10.1016/j.jtemb.2005.02.010.

7. Gray N F. Environmental impact and remediation of acid mine drainage: a management problem. Environ Geol. 1997 Mar;30(1-2):62-71, doi: 10.1007/s002540050133.

8. Chen KF, Kao CM, Chen TY, Weng CH, Tsai CT. Intrinsic bioremediation of MTBE-contaminated groundwater at a petroleum-hydrocarbon spill site. Environ Geol. 2006 Jun;50:439-445, doi: $10.1007 / \mathrm{s} 00254-006-0227-\mathrm{z}$.

9. El Fantroussi S, Agathos SN. Is bioaugmentation a feasible strategy for pollutant removal and site remediation? Curr Opin Microbiol. 2005 Jun;8(3):268-275, doi: 10.1016/j.mib.2005.04.011.

10. Anand P, Isar J, Saran S, Saxena RK. Bioaccumulation of copper by Trichoderma viride. Bioresour Technol. 2005 Nov;97(8):1018-1025, doi: 10.1016/j.biortech.2005.04.046.

11. Briuns MR, Kapil S, Oehme FW. Microbial resistance to metals in the environment. Ecotoxicol Environ Safety. 2000 Mar;45(3):198-207, doi: 10.1006/eesa.1999.1860.

12. Lima RA, Andrade RFS, Santos LQ, Takaki GMC. Produção de biossurfactante por Pseudomonas fluorescens em caldo de abacaxi (Ananas comosus) com óleo de girassol pós-fritura e aplicação na remoção de derivado do petróleo. Exacta. 2010;8(2):201-210, doi: 10.5585/exacta.v8i2.2186.

13. Santos SC, Fernandez LG, Rossi-Alva JC, Roque MRA. Evaluation of substrates from renewableresources in biosurfactants production by Pseudomonas strains. Afr J Biotechnol. 2010 Aug;9(35):57045711, doi: 10.5897/AJB10.201.

14. Thavasi R, Subramanyam Nambaru VRM, Jayalakshmi S, Balasubramanian T, Banat IM. Biosurfactant production by Pseudomonas aeruginosa from renewable resources. Indian J Microbiol. 2011 Jan;51(1):30-36, doi: 10.1007/s12088-011-0076-7.

15. Aş̧̧i Y, Nurbaş M, Açıkel YS. A comparative study for the sorption of Cd(II) by soils with different clay contents and mineralogy and the recovery of Cd(II) using rhamnolipid biosurfactant. J Hazd Mater. 2008 Jun;154(1-3):663-673, doi: 10.1016/j.jhazmat.2007.10.078.

16. Banat IM, Franzetti A, Gandolfi I, Bestetti G, Martinotti MG, Fracchia L, Smyth TJ, Marchant R. Microbial biosurfactants production, applications and future potential. Appl Microbiol Biotechnol. 2010 Jun;87(2):427-444, doi: 10.1007/s00253-010-2589-0.

17. Rufino RD, Rodrigues GIB, Campos-Takaki GM, Sarubbo LA, Ferreira SRM. Application of a yeast biosurfactant in the removal of heavy metals and hydrophobic contaminant in a soil used as slurry barrier. Appl Environ Soil Sci. 2011 Oct;2011:1-7, doi: 10.1155/2011/939648.

18. Aparna A, Srinikethan G, Smitha H. Production and characterization of biosurfactant produced by a novel Pseudomonas sp. 2B. Colloids Surf B. 2012 Jun;95(12):23-29, doi: 10.1016/j.colsurfb.2012.01.043. 
19. Santos SC, Oliveira LKX, Santos SN, Santos NPC, Quintella CM, Almeida PF, Fernandez LG, RossiAlva JC, Roque MRA. Biosurfactant production from Pseudomonas strains isolated in rhizospheric soils from semi-arid area of Bahia, Brazil. Sitientibus, Sér Ciênc Biol. 2012 Jun;12(1):157-163, doi: $10.13102 / \mathrm{scb} 121$.

20. Moraga R, Merino C, Mondaca MA. Resistencia a metales pesados en bacterias aisladas de la bahía de Iquique. Invest. 2003 Mar;31(1):91-95, doi: 10.4067/S0717-71782003000100010.

21. Echavez FLC, Leal JCM. Comparación de la ecotoxicidad por metales pesados sobre bacterias heterótrofas de dos sitios contrastados del lago de Maracaibo (Venezuela). Rev Fac Cienc Básicas. 2018;14(1):1-9, doi: 10.18359/rfcb.2825.

22. Hamme JDV, Singh A, Ward OP. Physiological aspects Part 1 in a series of papers devoted to surfactants in microbiology and biotechnology. Biotechnol Adv. 2006 Nov-Dec;24(6):604-620, doi: 10.1016/j.biotechadv.2006.08.001.

23. Mohr LC, Capelezzo AP, Rippel T, Ternus RZ, Dalcanton F, Fiori MA, Mello JMM. Efeito antimicrobiano de nanopartículas de $\mathrm{ZnO}$ e $\mathrm{TiO} 2$ frente as bactérias $S$. aureus e E. coli. Rev CSBEA. 2017;3(1):1-10, doi: 10.5965/24473650312017011.

24. Bodour AA, Miller-Maier RM. Application of a modified drop-collapse technique for surfactant quantitation and screening of biosurfactant-producing microorganisms. J Microbiol Meth. 1998 May;32(3):273-280, doi: 10.1016/S0167-7012(98)00031-1.

25. Luna JM, Rufino RD, Sarubbo LA, Campos-Takaki GM. Characterisation, surface properties and biological activity of a biosurfactant produced from industrial waste by Candida sphaerica UCP0995 for application in the petroleum industry. Colloids Surf B. 2013 Feb;102(1):202-209, doi: 10.1016/j.colsurfb.2012.08.008.

26. Song B, Springer J. Determination of Interfacial tension from the profile of a pendant drop using computer-aided image processing. J Colloid Interface Sci. 1996 Dec;184(1):77-91, doi: 10.1006/jcis.1996.0597.

27. Chen C-Y, Baker SC, Darton RC. The application of a high throughput analysis method for the screening of potential biosurfactants from natural sources. J Microbiol Meth. 2007 Sep;70(3):503-510, doi: 10.1016/j.mimet.2007.06.006.

28. Alhasawi A, Costanzi J, Auger C, Appanna ND, Appanna VD. Metabolic reconfigurations aimed at the detoxification of a multi-metal stress in Pseudomonas fluorescens: implications for the bioremediation of metal pollutants. J Biotechnol. 2015 Apr;200:38-43, doi: 10.1016/j.jbiotec.2015.01.029.

29. Cárdenas OGG, Ibarra LFN, Lara PDL, Rodríguez OGR, Mejía RJ. Perfiles de resistencia a antibióticos y metales pesados en Pseudomonas aeruginosa potencialmente patógenas aisladas de agua de uso agrícola antibiotic and heavy metal resistance profiles in potentially pathogenic $P$ seudomonas aeruginosa isolated from agrícola. Nova Sci. 2017;9(19):97-112, doi: 10.21640/ns.v9i19.957.

30. Chenia HY, Jacobs A. Antimicrobial resistance, heavy metal resistance and integron content in bacteria isolated from a South African tilapia aquaculture system. Dis Aquat Organ. 2017 Nov;126(3):199-209, doi: $10.3354 /$ dao03173.

31. Poirier I, Jean N, Guary JC, Bertrand M. Responses of the marine bacterium Pseudomonas fluorescens to an excess of heavy metals: physiological and biochemical aspects. Sci Total Environ. 2008 Nov;406(12):76-87, doi: 10.1016/j.scitotenv.2008.07.038.

32. Andrade JIA, Augusto F, Jardim ICSF. Biorremediação de solos contaminados por petróleo e seus derivados. Eclét. Quím. 2010 Sep;35(3):17-43, doi: 10.1590/S0100-46702010000300002.

33. Malik A. Metal bioremediation through growing cells. Environ Int. 2004 Apr;30(2):261-278, doi: 10.1016/j.envint.2003.08.001.

34. Zafar S, Aqil F, Ahmad I. Metal tolerance and biosorption potential of filamentous fungi isolated from metal contaminated agricultural soil. Bioresour Technol. 2007 Sep;98(13):2557-2561, doi: 10.1016/j.biortech.2006.09.051.

35. Rouch DA, Lee BTO, Morby AP. Understanding cellular responses to toxic agents: a model for mechanism-choice in bacterial metal resistance. J Ind Microbiol. 1995 Feb;14(2):132-41, doi: $10.1007 / \mathrm{bf0} 01569895$.

36. Melo IS, Azevedo JL. Microbiologia ambiental. 2. ed. Jaguariúna: Embrapa Meio Ambiente; 2008. 647p.

37. Rodríguez-Sánchez V, Guzmán-Moreno J, Rodríguez-González V, Flores-de la Torre JA, RamírezSantoyo RM, Vidales-Rodríguez LE. Biosorption of lead phosphates by lead-tolerant bacteria as a mechanism for lead immobilization. World J Microbiol Biotechnol. 2017 Aug;33(8):1-11, doi: 10.1007/s11274-017-2314-6.

38. Melo Santos SF, Melo ALM, Lima AO, Pereira LMS, Santos FA, Medeiros NM, Silva MGB. Avaliação da produção de biossurfactante a partir de diferentes fontes de carbono por Candida guilliermondii. Rev Saúde Ciênc. 2018 May-Aug;7(2):413-425, doi: 10.35572/rsc.v7i2.650. 
39. Pinto MH, Martins RG, Costa JAV. Avaliação cinética da produção de biossurfactantes bacterianos. Quim Nova. 2009 Aug;32(8):2104-2108, doi: 10.1590/S0100-40422009000800022.

40. Rizzo C, Michaud L, Graziano M, De Domenico E, Syldatk C, Hausmann R, Giudice AL. Biosurfactant activity, heavy metal tolerance and characterization of Joostella strain A8 from the Mediterranean polychaete Megalomma claparedei (Gravier, 1906). Ecotoxicol. 2015 Aug;24(6):1294-304, doi: 10.1007/s10646-015-1504-y.

41. Rizzo C, Giudice AL. Heavy metal tolerance and chelating activity of bacteria associated with mediterranean polychaetes. Sci Forecast Publ. 2018;1(2):1-4.

42. Desai JD, Banat IM. Microbial production of surfactants and their commercial potential. Microbiol Mol Biol Rev. 1997 Mar;61(1):47-64, doi: 10.1128/.61.1.47-64.1997.

43. El-Sheshtawy HS, Doheim MM. Selection of Pseudomonas aeruginosa for biosurfactant production and studies of its antimicrobial activity. Egyptian J Petroleum. 2014 Mar;23(1):1-6, doi: 10.1016/j.ejpe.2014.02.001.

44. Rizzo C, Rappazzo AC, Michaud L, Domenico E, Rochera C, Camacho A, Giudice AL. Efficiency in hydrocarbon degradation and biosurfactant production by Joostella sp. A8 when grown in pure culture and consortia. J Environ Sci. 2018 May;67:115-126, doi: 10.1016/j.jes.2017.08.007. 